\title{
Assessment of the virulence and proteolytic activity of three native entomopathogenic fungi against the larvae of Oryctes agamemnon (Burmeister) (Coleoptera: Scarabaeidae)
}

\author{
Abdel-Rahman Saleem ${ }^{1,2^{*}}$ and Reda A. Ibrahim ${ }^{1,3}$
}

\begin{abstract}
Susceptibility of the third larval instar of the rhinoceros beetle, Oryctes agamemnon (Burmeister) (Coleoptera: Scarabaeidae), to the infection with three native entomopathogenic fungi (EPFs), Beauveria bassiana, Metarhizium anisopliae, and Lecanicillium lecanii, was determined under laboratory conditions. Three concentrations $\left(10^{4}, 10^{6}\right.$, and $10^{8}$ conidia/ml) of each EPF isolate were tested. Respective mortality rates of the larvae reached $34.2,48.1$, and 55.5\% for B. bassiana, 39.5, 57.4, and 60.8\% for M. anisopliae, and 17.4, 26.4, and 29.2\% for L. lecanii. Mycosis test was performed to confirm the fungal infection of dead larvae. The $L T_{50}$ values for $O$. agamemnon larvae were 9.9 and 11.3 days, for the concentration which achieved $50 \%$ mortality for B. bassiana and M. anisopliae, respectively. The proteolytic activity of the three EPFs was investigated under different factors (incubation periods, temperature, and $\mathrm{pH}$ of fungal cultures). The results showed that the maximum activity of protease, produced by the three EPFs, was recorded after 6 days of incubation periods at $28^{\circ} \mathrm{C}$, in a medium initially adjusted to $\mathrm{pH} 6$.
\end{abstract}

Keywords: Oryctes agamemnon, Entomopathogenic fungi, Virulence, Protease activity

\section{Background}

Date palms, Phoenix dactylifera L., are attacked by several insect pests. Among these insects, several species of the genus Oryctes (Coleoptera: Scarabaeidae), such as Oryctes elegans, O. agamemnon, and O. rhinoceros, infesting the date palm orchards of many Arabian countries (Khalaf et al. 2013; Ibrahim 2017). In the past few years, rhinoceros beetles, Oryctes spp., have been recorded as major pests of different date palm varieties. The most widespread species is O. agamemnon (Burmeister), which is a root borer in its larval stage and a frond borer in the adult stage. Both adults and larvae of Oryctes are particularly troublesome, principally during

\footnotetext{
* Correspondence: asaleem@hotmail.com

${ }^{1}$ Biology Department, Faculty of Science, Taibah University, Almadinah Almunawarah 344, Saudi Arabia

${ }^{2}$ Botany Department, Faculty of Science, South Valley University, Qena 83523, Egypt

Full list of author information is available at the end of the article
}

the establishment of young date palm orchards (Ibrahim and Alahmadi 2015). The larvae feed on roots and rotten woods, whereas adults feed on the plant's sap and fruits. Development of the larvae is long and may extend for several years in some species (Bedford 1980).

At present, the management of O. agamemnon in date palm orchard is either non-existent (by small scale farmers) or relies on the application of insecticides in large areas, such as carbofuran and certain biocontrol agents (Zelazny et al. 1992). Several studies were carried out to control Oryctes either through using botanicals (Ibrahim and Alahmadi 2015) or determination of distinct endosymbiotic community structure and its possible biological functions within the insect to conclude basic information for future pest control (El-Sayed and Ibrahim 2015). Recently, certain entomopathogenic fungi such as Beauveria bassiana, Metarhizium anisopliae, and Lecanicillium lecanii have been applied against 
Oryctes and resulted in satisfactory mortalities to both adults and larvae of the pest (Ibrahim 2017).

Entomopathogenic fungi (EPFs) produce a variety of degrading enzymes, including proteases, chitinases, and lipases, to facilitate the entry through the massive barriers of insect cuticle. These fungi varied in their proteolytic activity and virulence. The proteolytic activity of different isolates has reflected their virulence to the host (Zare et al. 2014). EPFs enter the insect's body mainly through their integument (Balachander et al. 2012). The insect cuticle comprises up to $70 \%$ protein, thus extracellular fungal proteases are particularly important for the penetration process (Petrisor and Stoian 2017). The three common EPFs, B. bassiana, $M$. anisopliae, and L. lecanii (formerly known as Verticillium lecanii), produce a variety of extracellular hydrolytic enzymes in liquid cultures. Recent evidence indicates that the different species or isolates of the EPFs exhibited variation in the production of cuticle-degrading proteases (Dhar and Kaur 2010; Zare et al. 2014; Dhawan and Joshi 2017). Isolates with high proteolytic activity have high virulence against their host. For instance, Zare et al. (2014) evaluated the virulence and proteolytic activity of 17 native isolates of B. bassiana and found that mortalities caused by such isolates ranged $25-60 \%$. A wide variation in both proteolytic activity and virulence among the isolates were recorded.

The present study was carried out to evaluate the virulence and proteolytic activity of the three native entomopathogenic fungi (EPFs) namely, B. bassiana, M. anisopliae, and $L$. lecanii, against the third larval instar of O. agamemnon under laboratory conditions.

\section{Materials and methods}

Isolation of entomopathogenic fungi

The EPFs were isolated from rhizosphere soil of palm trees collected from an infested date palm orchard, approximately $80 \mathrm{~km}$ north of Al Madinah region of Saudi Arabia. Soil samples were collected from different locations. The samples were placed in sterilized polyethylene bags and stored at $4{ }^{\circ} \mathrm{C}$ until fungal analysis.

\section{Selective medium used for isolation of entomopathogenic fungi}

Selective medium (DOC2) containing $3 \mathrm{~g}$ peptone, $0.2 \mathrm{~g}$ $\mathrm{CuCl}_{2}, 2 \mathrm{mg}$ crystal violet, $0.5 \mathrm{~g}$ chloramphenicol, $50 \mathrm{~g}$ oat, and $15 \mathrm{~g}$ agar which required for isolation of the EPFs from the soil was used (Liu et al. 2015).

\section{Identification of fungi}

The EPFs recovered from the above medium were investigated, using a light microscope, for characteristics of their vegetative and reproductive structures such as hyphal color and structures and shape and size of conidia and conidiophores (Humber 1997).

\section{Preparation of spore suspensions}

The EPFs, B. bassiana, M. anisopliae, and L. lecanii, were cultured on potato dextrose agar (PDA) medium for 10 days at $25^{\circ} \mathrm{C}$. Spores were harvested from the surface of cultures by scraping and used for preparation of spore suspensions (distilled water containing $0.1 \%$ Tween 80 ). The spore concentrations were calibrated to $1 \times 10^{4}, 1 \times 10^{6}$, and $1 \times 10^{8}$ spores $/ \mathrm{ml}$ using a hemocytometer. These suspensions represented the stock for insect treatment.

\section{Insects}

Larvae of O. agamemnon were collected from an infested date palm orchard, and the third larval instar was dominant in the samples. The larvae were kept in sterilized plastic containers. In order to minimize any potential insecticide residual effect and to avoid possible infections from the field, larvae were kept in the laboratory for 1 week prior to treatment with EPFs. Bioassays were carried out under laboratory conditions. Groups of 10 larvae were reared in plastic containers half-filled with moist soil and shredded fragments of palm roots.

\section{Treatment of the third instar O. agamemnon larvae with EPF isolates}

Three conidial concentrations $\left(1 \times 10^{4}, 1 \times 10^{6}\right.$, and $1 \times$ $10^{8}$ conidia/ml) of each EPF were assayed against the third instar larvae of $O$. agamemnon. Since white grubs prefer soil with loamy or sandy textures, the test soil was taken from a $30-50-\mathrm{cm}$ depth in palm orchards and heat-sterilized at $160^{\circ} \mathrm{C}$ for $2 \mathrm{~h}$ in an oven. Then, sterile water was added to the heat-sterilized soil to reach $17 \%$ moisture content (Nong et al. 2011). Larval infection's procedures and tools of Nong et al. (2011) and Ibrahim (2017) were adopted with minor modification. Ten O. agamemnon larvae were placed in a plastic container (five replicates). A control treatment was also used in each bioassay. The plastic containers were kept for 30 days at $\left(23 \pm 2{ }^{\circ} \mathrm{C}, 60-75 \% \mathrm{RH}\right)$. Each container was checked daily for dead larvae. For each EPF isolate, the infection percentage of $O$. agamemnon larvae was corrected for mortality, according to Abbott (1925). In order to confirm mycosis, dead larvae were counted, moved to Petri dishes furnished with a moistened filter paper, and incubated at $25 \pm 2{ }^{\circ} \mathrm{C}$ for 10 days, and the developed fungi were examined and identified (mycosis test).

\section{Proteolytic activity of the EPF isolates Screening of EPF isolates for protease activity}

The tested three fungi were screened for their abilities to produce extracellular protease enzyme. Fifty milliliters of casein yeast extract broth with ingredients (grams per liter) casein 30.0, yeast extract 4.0, dipotassium phosphate, 0.5 and dextrose $2.0\left(\mathrm{pH}\right.$ at $\left.25^{\circ} \mathrm{C}, 7.2 \pm 0.2\right)$ was dispensed into a 250-ml Erlenmeyer conical flasks and autoclaved for 15 
min at $1.5 \mathrm{~atm}$. Each flask was inoculated with two agar mycelial discs (10-mm diameter) of tested fungi obtained from 7-day-old cultures growing on the same agar medium. Cultures were incubated at $28^{\circ} \mathrm{C}$ for 7 days. Then the mycelium was harvested by filtration. Filtrates were centrifuged at $5000 \mathrm{rpm}$ for $10 \mathrm{~min}$, and the supernatants were assayed for proteolytic activity, according to the method of casein agar cup plate clearing zone assay (El-Gendy 1966) as follows: aliquots of $0.2 \mathrm{ml}$ of the above filtrate was dropped into $10-\mathrm{mm}$ cavities previously made in the above solid medium. After $48 \mathrm{~h}$ of incubation at $28^{\circ} \mathrm{C}$, the plates were folded with $5 \%$ trichloroacetic acid solution. The average diameter of clear zone (in millimeter) of triplicate was measured.

\section{Effect of different factors on the proteolytic activity of EPF isolates}

The effect of different factors on the proteolytic activity of the EPF was measured. These factors included incubation periods, temperature, and $\mathrm{pH}$ of fungal cultures. For incubation periods, $50 \mathrm{ml}$ of the casein yeast extract broth was inoculated by two mycelial discs (10-mm diameter) of fungi and incubated at $28^{\circ}$ C. The cultures were harvested at $48 \mathrm{~h}$ intervals. For temperature, $50 \mathrm{ml}$ of medium was inoculated by two mycelial discs of fungi and incubated at different temperatures $\left(20,24,28,32,36\right.$, or $\left.40^{\circ} \mathrm{C}\right)$. For $\mathrm{pH}$, the initial $\mathrm{pH}$ of the casein yeast extract broth was adjusted to different values ranging from 4 to 9 and inoculated with two mycelial discs of fungi. The cultures were incubated at $28^{\circ} \mathrm{C}$ for 6 days. The cultures were filtered and centrifuged at $5000 \mathrm{rpm}$ for $10 \mathrm{~min}$. The clear supernatants were assayed for protease activity. All experiments were done in three replicates.

\section{Assay for protease activity}

Protease activity was determined according to the method described by Sumantha et al. (2006). This method is based on casein hydrolysis in which casein is used as a substrate. The release of soluble tyrosine was estimated by Folin reagent. The activity was calculated from the difference between the control and the experimental titration values. Enzyme activity was expressed by units of L-tyrosine liberated during the reaction. The units were determined by a standard curve early constructed, using different concentrations of L-tyrosine.

\section{Statistical analysis}

Statistical analysis of data was carried out by one-way analysis of variance. The means and standard error were separated by Tukey's honest significant difference test $(P<0.05)$, using Biostat 2008 statistical analysis program (Copyright@ 2001-2009 Analystsoft).

\section{Results and discussion \\ Virulence of EPF isolates against the third instar $O$. agamemnon larvae}

The tested EPF isolates differed in their virulence to the larvae of the pest (Table 1). Their efficacy against the third instar O. agamemnon larvae increased significantly by increasing concentration and elapsed time $(P \leq 0.05)$ (up to 4 weeks after treatment). For example, on the seventh day after treatment, mortality rates of the larvae recorded $21.3,16.6$, and $10.1 \%$ at the concentration of $1 \times 10^{8}$ conidia/ml of $M$. anisopliae, B. bassiana, and $L$. lecanii, respectively (Table 1 ). Whereas, after 28 days of treatment at the same concentration, the respective accumulated mortality recorded $60.8,55.5$, and $29.2 \%$. In a similar study, using commercial formulations of $B$.

Table 1 Mortality percentages (\% \pm SE) of the third instar Oryctes agamemnon larvae treated with entomopathogenic fungi (EPFs) Beauveria bassiana, Lecanicillium lecanii, and Metarhizium anisopliae

\begin{tabular}{|c|c|c|c|c|c|}
\hline \multirow[t]{2}{*}{ EPFs } & \multirow[t]{2}{*}{ Concentrations (conidia/ml) } & \multicolumn{4}{|c|}{ Days after treatment } \\
\hline & & 7 & 14 & 21 & 28 \\
\hline \multirow[t]{3}{*}{ Beauveria bassiana } & $1 \times 10^{4}$ & $11.7^{*} \pm 1.3$ & $21.4^{*} \pm 4.2$ & $28.8^{*} \pm 3.5$ & $34.2^{*} \pm 2.1$ \\
\hline & $1 \times 10^{6}$ & $14.2^{*} \pm 2.4$ & $24.4^{*} \pm 3.2$ & $39.6^{*} \pm 4.1$ & $48.1^{*} \pm 3.1$ \\
\hline & $1 \times 10^{8}$ & $16.6^{*} \pm 3.1$ & $29.7^{*} \pm 2.9$ & $41.2^{*} \pm 3.3$ & $55.5^{*} \pm 4.3$ \\
\hline \multirow[t]{3}{*}{ Metarhizium anisopliae } & $1 \times 10^{4}$ & $12.3^{*} \pm 2.3$ & $24.5^{*} \pm 3.1$ & $32.9^{*} \pm 3.1$ & $39.5^{*} \pm 3.7$ \\
\hline & $1 \times 10^{6}$ & $16.9^{*} \pm 3.1$ & $33.6^{*} \pm 3.5$ & $44.2^{*} \pm 4.2$ & $57.4^{*} \pm 3.2$ \\
\hline & $1 \times 10^{8}$ & $21.3^{*} \pm 3.6$ & $40.8^{*} \pm 4.6$ & $51.1^{*} \pm 3.5$ & $60.8^{*} \pm 2.6$ \\
\hline \multirow[t]{3}{*}{ Lecanicillium lecanii } & $1 \times 10^{4}$ & $3.8 \pm 1.4$ & $7.2 \pm 4.4$ & $13.9^{*} \pm 3.3$ & $17.4^{*} \pm 2.1$ \\
\hline & $1 \times 10^{6}$ & $6.7 \pm 2.1$ & $13.3^{*} \pm 3.2$ & $20.4^{*} \pm 3.5$ & $26.4^{*} \pm 3.2$ \\
\hline & $1 \times 10^{8}$ & $10.1^{*} \pm 2.2$ & $17.5^{*} \pm 3.3$ & $22.6^{*} \pm 4.1$ & $29.2^{*} \pm 4.1$ \\
\hline Control & - & $0.0 \pm 0.0$ & $0.0 \pm 0.0$ & $0.0 \pm 0.0$ & $0.0 \pm 0.0$ \\
\hline
\end{tabular}

Asterisked values mean significant difference compared to the control $(P \leq 0.05)$ 


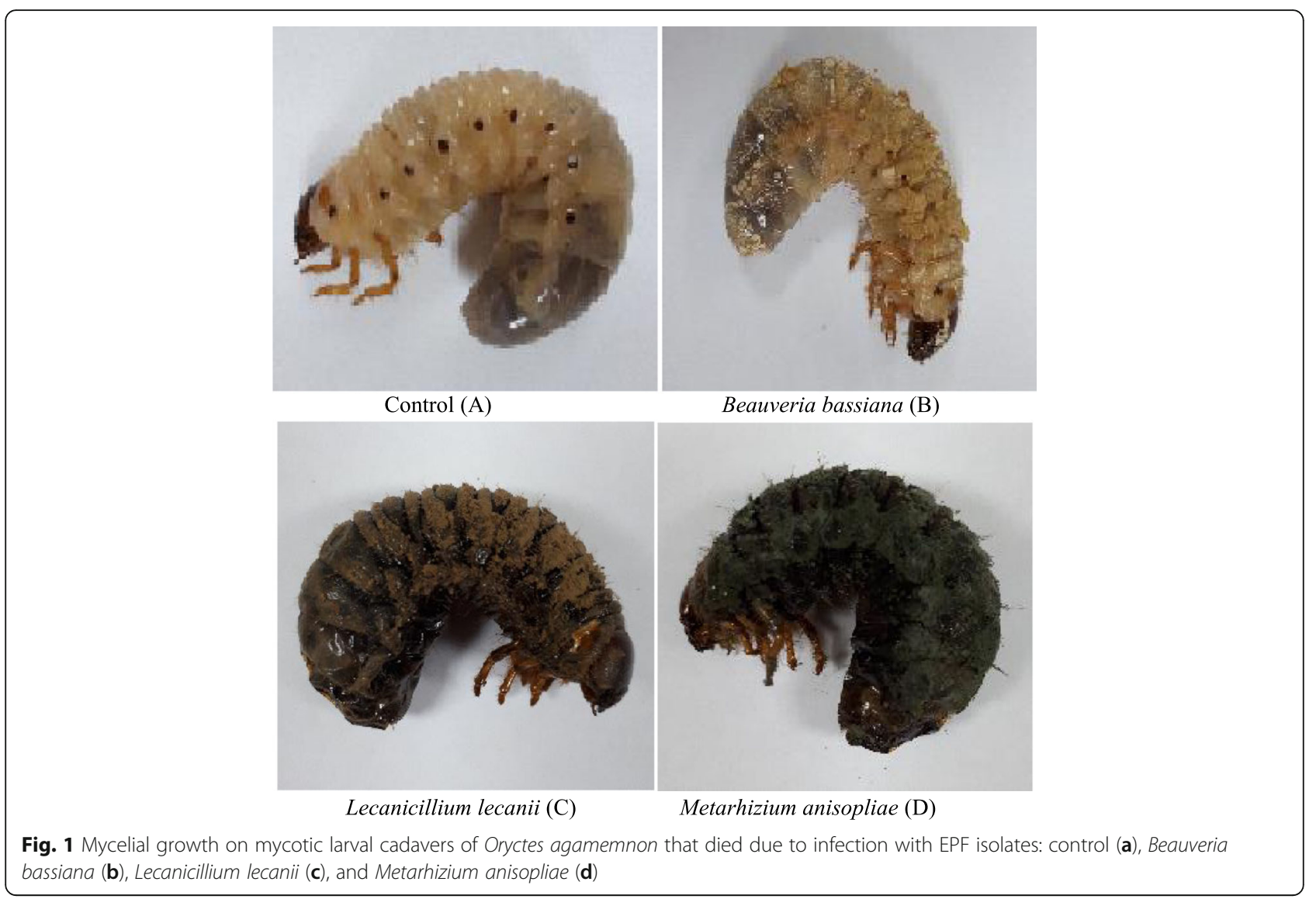

bassiana and M. anisopliae against the larvae of $O$. agamemnon (Ibrahim 2017), mortality rates reached 9.7 and $16.5 \%$ on the fifth day after treatment, respectively. In comparison, native isolates were more virulent than commercial formulations of the same EPF species (Ibrahim 2017). A commercial product based on M. anisopliae was tested by Pernfuss et al. (2005) against a scarab species, Phyllopertha horticola, where it recorded $14 \%$ larval mortality. It could be concluded that native species, as expected, to be well adapted to local conditions. Similarly, in Malaysia, Azmi et al. (2016) tested native isolates against termites and reported that $M$. anisopliae was the most virulent one, followed by strains of B. bassiana and Paecilomyces sp. at $10^{7}$ concentration. The efficacy of EPFs was increased by increasing the concentration and elapsed time. $M$. anisopliae infected the larvae of $O$. agamemnon significantly faster, followed by B. bassiana and $L$. lecanii. Regarding the accumulated mortality rate at the concentration $1 \times 10^{8}$ conidia $/ \mathrm{ml}$ on the 28 th day after treatment, $M$. anisopliae was the most effective one, recording $60.8 \%$, followed by those of $B$. bassiana and L. lecanii that achieved 55.5 and $29.2 \%$, respectively $(P \leq 0.05)$. In Iraq, in comparison, a $100 \%$ mortality was achieved by two local isolates namely, $M$. anisopliae and B. bassiana against the larvae of O. agamemnon arabicus (Khudhair et al. 2015).
In a similar study, 12 isolates of B. bassiana, $M$. anisopliae, and Isaria fumosorosea were tested against the third instar larvae of Plagiodera versicolora in the laboratory and B. bassiana achieved $100 \%$ mortality (Demir et al. 2013). Similarly, Berón and Diaz (2005) recorded a higher virulence of $B$. bassiana than other isolates against certain soil-dwelling insect pests. The variations among EPFs efficacy may be due to either differences in conidial viability and concentrations, rates of inducing proliferation, or the susceptibility of pest or its enzymatic activity (Mondal 2016). Zhang et al. (2011) found a positive correlation between germination, growth rate, and sporulation of $B$. bassiana and its virulence to red turpentine beetle larvae. Moreover, proteins of the P450 family were identified as

Table $\mathbf{2} L T_{50}$ of entomopathogenic fungi (EPFs) at the indicated concentration applied against the third instar Oryctes agamemnon larvae

\begin{tabular}{lcc}
\hline EPFs & \multicolumn{2}{l}{ Third instar larvae } \\
\cline { 2 - 3 } & $\mathrm{LT}_{50}$ (days) & Slope $\pm \mathrm{SE}$ \\
\hline Beauveria bassiana & 9.9 & $0.3 \pm 0.26$ \\
$1 \times 10^{8}$ conidia/ml & & \\
Metarhizium anisopliae & 11.3 & $0.5 \pm 0.12$ \\
$1 \times 10^{8}$ conidia/ml &
\end{tabular}




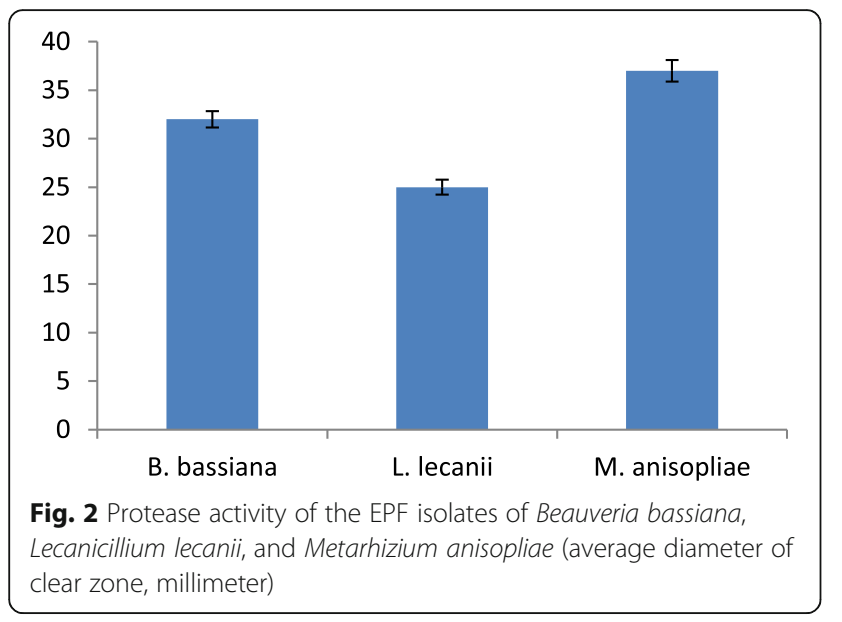

necessary for cuticle degradation (Pedrini et al. 2010; Zhang et al. 2012).

\section{Morphological observations of EPFs mycelial growth}

The first symptoms of disease were observed in $O$. agamemnon larvae about 6 to 7 days after infection. The EPFs had most commonly penetrated the larvae directly through the intersegmental areas. Prior to host death of the larvae, the EPFs developed sparsely within the body cavity and some hyphae radiated inward from the point of ingress (Fig. 1). Hyphal bodies were concentrated near the point of ingress, but a few were found remote from this site. After the death of the larvae, the EPFs developed the saprophytic phase rapidly. During the saprophytic phase, the emergence of conidiophores appeared unrestricted in its points of emergence from the host and seemed to rupture the cuticle by mechanical pressure on egress. The sporulation was realized $24-48 \mathrm{~h}$ after emergence. Generally, the sign of penetration of the larval cuticle by $M$. anisopliae appeared faster than $B$. bassiana and $L$. lecanii. After the penetration, the EPFs appeared to break through the cuticle and conidia emerged on the surfaces of the cadavers (Fig. 1).

\section{$\mathrm{LT}_{50}$ of tested EPFs against the third instar larvae of $O$. agamemnon}

The $\mathrm{LT}_{50}$ values of the third instar O. agamemnon larvae ranged from 9.9 to 11.3 days for the tested concentrations of M. anisopliae and B. bassiana that caused 50\% mortality, respectively (Table 2). However, since the mortality rate of the third instar larvae, treated with $L$. lecanii, was lower than $50 \%$. It was not calculated at the concentration of $10^{8}$. In a similar study, Khudhair et al. (2015) reported that the $\mathrm{LT}_{50}$ value for $O$. agamemnon arabicus larvae treated with $B$. bassiana was 12.75 days. Latifian and Rad (2012) found that the $\mathrm{LT}_{50}$ in adults of $O$. elegans ranged 7.21-11.62 days for B. bassiana, 6.45-10.12 days for $B$. brongniartii, and 6.05-10.89 days for M. anisopliae.

\section{Proteolytic activity of EPF isolates}

In terms of protease production, $M$. anisopliae was the most active fungal isolate among the tested ones. $M$. anisopliae produced $37-\mathrm{mm}$ clear zone diameter, followed by B. bassiana (32 $\mathrm{mm} \varnothing)$, and L. lecanii $(25 \mathrm{~mm} \varnothing)$ using casein as substrate (Fig. 2). Proteolytic activity of the three EPF isolates was similar to that reported by Petlamul and Prasertsa (2012). Different assays were performed to detect protease production by EPFs in cultures (Ali et al. 2011: Dhawan and Joshi 2017). The high level of protease activity was detected in the culture filtrate of M. anisopliae (Petrisor and Stoian 2017) and B. bassiana (Donatti et al. 2008). As expected, the highest proteolytic activity isolate was the most virulent one against $O$. agamemnon larvae.

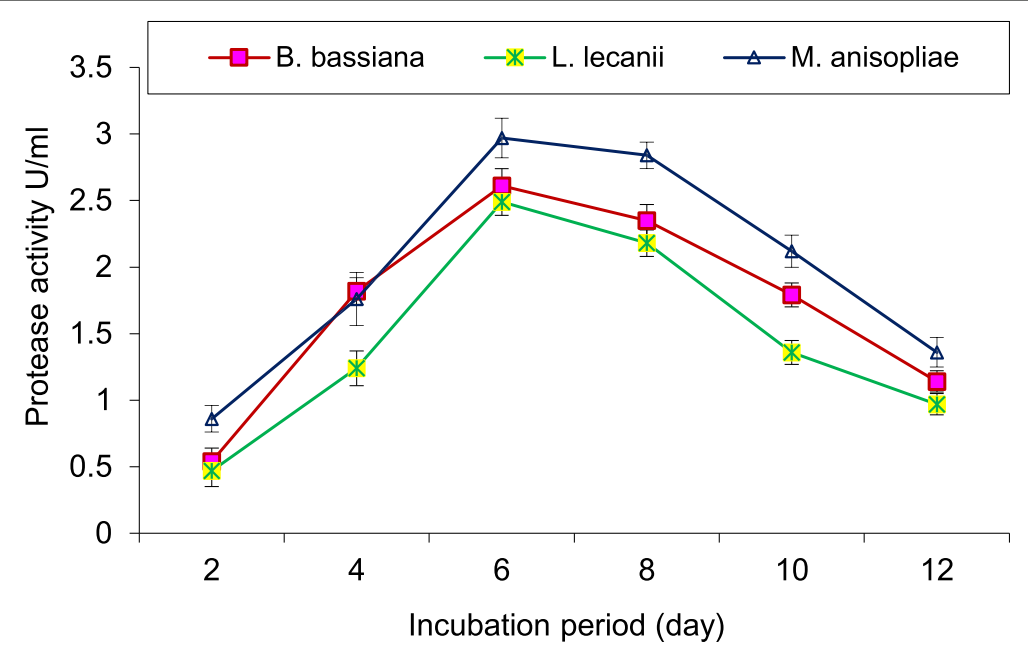

Fig. 3 Effect of incubation period on protease activity of the EPF isolates of Beauveria bassiana, Lecanicillium lecanii, and Metarhizium anisopliae 


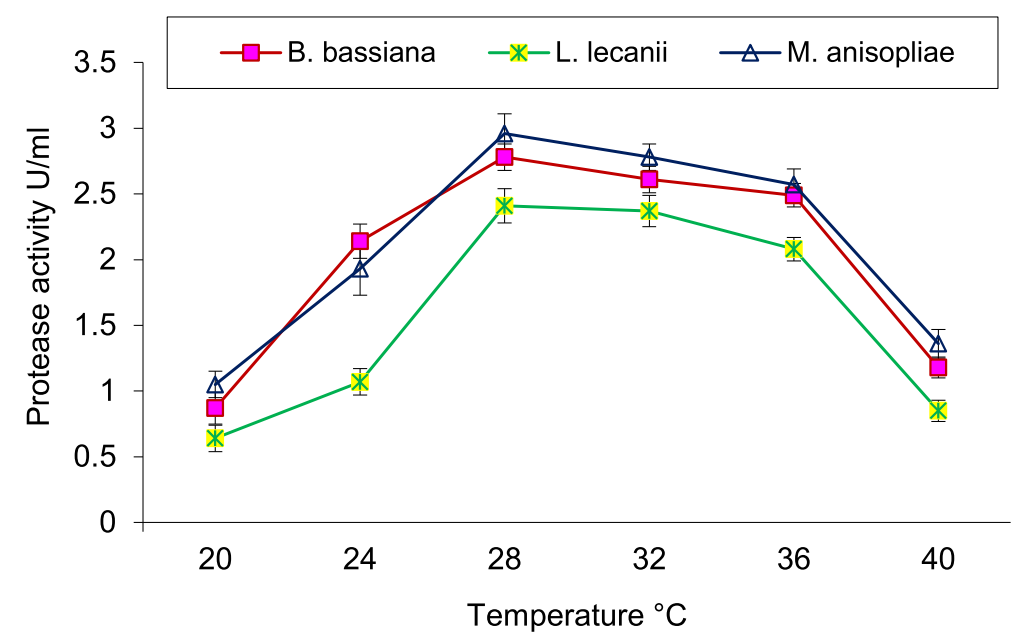

Fig. 4 Effect of temperature on protease activity of the EPF isolates of Beauveria bassiana, Lecanicillium lecanii, and Metarhizium anisopliae

\section{Effect of limiting factors on the proteolytic activity of EPF isolates \\ Effect of incubation period}

Proteolytic activity of the EPFs tested was affected by the incubation time of fungal cultures. Protease activity of the isolates was variable with different incubation periods. Maximum protease activity was achieved after 6 days of incubation for B. bassiana $(2.61 \mathrm{U} / \mathrm{ml})$, L. lecanii $(2.49 \mathrm{U} / \mathrm{ml})$, and $M$. anisopliae $(2.97 \mathrm{U} / \mathrm{ml})$. The enzyme activity decreased when the incubation periods decreased or increased above the optimum time (Fig. 3). The obtained results were in agreement with those reported by Khan et al. (2012). They screened the proteolytic activity of six EPF isolates, three isolates from each of $B$. bassiana and $V$. lecanii. They found that the optimum incubation period for protease activity was 4-6 days. Recently, Dhawan and Joshi (2017) recorded the maximum protease activity of $B$. bassiana to be $6-8$ days of incubation.

\section{Effect of temperature}

The proteolytic activity of the tested EPFs was greatly influenced by incubation temperature of fungal cultures. The effect of temperature on the proteolytic activity was variable. The optimum temperature for all fungi tested was $28^{\circ} \mathrm{C}$ : B. bassiana $(2.78 \mathrm{U} / \mathrm{ml})$, L. lecanii $(2.41 \mathrm{U} / \mathrm{ml})$, and $M$. anisopliae $(2.96 \mathrm{U} / \mathrm{ml})$. Decreasing or increasing the temperature below or above the optimum degree decreased the enzyme activity by all tested fungi (Fig. 4). In this respect, Ali et al. (2011) reported that the optimum temperature of protease activity for M. anisupliae was $35^{\circ} \mathrm{C}$.

\section{Effect of $p H$}

The proteolytic activity of the tested EPFs was affected by the hydrogen ion concentration of fungal cultures. Protease activity was varied by different $\mathrm{pH}$ values. The optimum $\mathrm{pH}$ for protease activity of EPFs was 6: $B$.

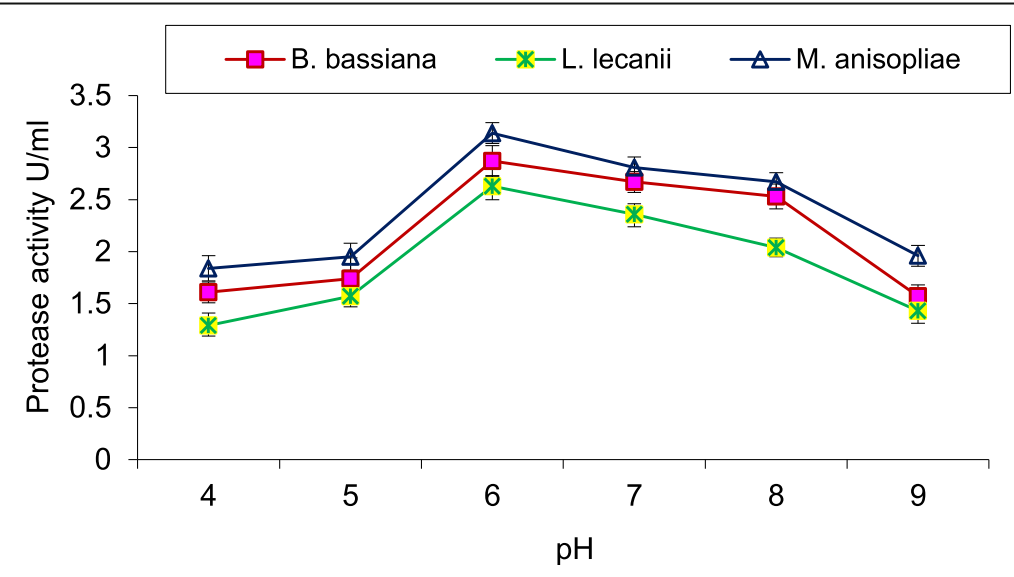

Fig. 5 Effect of pH on protease activity of the EPF isolates of Beauveria bassiana, Lecanicillium lecanii, and Metarhizium anisopliae 
bassiana $(2.87 \mathrm{U} / \mathrm{ml})$, L. lecanii $(2.63 \mathrm{U} / \mathrm{ml})$, and $M$. anisopliae $(3.14 \mathrm{U} / \mathrm{ml})$. The enzyme activity decreased with shifting the $\mathrm{pH}$ to more acidic or alkaline medium by the all tested fungi (Fig. 5). The obtained results were similar to those of Mishra et al. (2013). They recorded a maximum activity of protease produced by a native $B$. bassiana to be at pH 5-6. However, Ali et al. (2011) reported that the optimum extracellular protease activity of $M$. anisopliae was at $\mathrm{pH} 8$. On the other hand, Hasan et al. (2013) revealed that the highest proteolytic activity of the Verticillium lecanii was at pH 7-9.

\section{Conclusion}

In the study, $M$. anisopliae was the most virulent native EPFs against the third instar larvae of O. agamemnon compared to B. bassiana and L. lecanii. However, field trial should be conducted as the efficacy between laboratory and field conditions could greatly differ. Selecting an appropriate fungal isolate was highly relevant in controlling O. agamemnon larvae, particularly if used as part of an integrated pest management strategy. The variation observed in virulence among EPFs offers an opportunity to better understand the molecular and genetic mechanisms that drive this variation. However, more studies are needed than one way of application of EPF isolates under orchard conditions.

\section{Acknowledgements}

Taibah University, Saudi Arabia.

\section{Funding}

Not applicable

\section{Availability of data and materials \\ yes}

\section{Authors' contributions}

Both authors read and approved the final manuscript.

\section{Ethics approval and consent to participate}

yes

Consent for publication

yes

\section{Competing interests}

The authors declare that they have no competing interests.

\section{Publisher's Note}

Springer Nature remains neutral with regard to jurisdictional claims in published maps and institutional affiliations.

\section{Author details}

'Biology Department, Faculty of Science, Taibah University, Almadinah Almunawarah 344, Saudi Arabia. ${ }^{2}$ Botany Department, Faculty of Science, South Valley University, Qena 83523, Egypt. ${ }^{3}$ Department of Economic Entomology, Kafrelsheikh University, Kafr El-Sheikh 33516, Egypt.
Received: 29 November 2018 Accepted: 8 March 2019

Published online: 05 April 2019

\section{References}

Abbott WS (1925) A method of computing the effectiveness of an insecticide. J Econ Entomol 18:265-267

Ali S, Huang Z, QeZang W, Ren SX (2011) Production and regulation of extracellular proteases from the entomopathogenic fungus Metarhizium anisopliae (Cordycipitaceae; Hypocreales) in the presence of diamondback moth cuticle. Pak J Zool 43(6):1203-1213

Azmi WA, Sulaiman ZA, Ishak I, Kin PK, Lin GLE, Addis SNK (2016) Virulence evaluation of entomopathogenic fungi to subterranean termites, Globitermes sulphureus (Insecta: Isoptera). Malays J Microbiol 12(6):492-497

Balachander M, Remadevi OK, Sasidharan TO, Sapna BN (2012) Virulence and mycotoxic effects of Metarhizium anisopliae on mahogany shoot borer, Hypsipyla robusta (Lepidoptera: Pyralidae). J Forest Res 23:651-659

Bedford G (1980) Biology, ecology and control of palm rhinoceros beetles. Ann Rev Entomol 25:309-339

Berón C, Diaz B (2005) Pathogenicity of hyphomycetous fungi against Cyclocephalas ignaticollis. BioControl 50(1):143-150

Demir I, Kocaçevik S, Sönmez E, Demirbağ Z, Sevim A (2013) Virulence of entomopathogenic fungi against Plagiodera versicolora (Laicharting, 1781) (Coleoptera: Chrysomelidae). Afr J Agric Res 8(18):2016-2021

Dhar P, Kaur G (2010) Cuticle-degrading proteases produced by Metarhizium anisopliae and their induction in different media. Indian J Microbiol 50:449-455

Dhawan M, Joshi N (2017) Enzymatic comparison and mortality of Beauveria bassiana against cabbage caterpillar Pieris brassicae LINN. Braz J Microbiol 48: 522-529

Donatti AC, Furlaneto-maia L, Fungaro MHP, Furlaneto MC (2008) Production and regulation of cuticle-degrading proteases from Beauveria bassiana in the presence of Rhammatocerus schistocercoides cuticle. Current Microbiol 56: $256-260$

El-Gendy SM (1966) Microbial survey of blueveined cheese, Roqueforte-type. Bull Sci Technol 9:367-384

El-Sayed W, Ibrahim R (2015) Diversity and phylogenetic analysis of endosymbiotic bacteria of the date palm root borer Oryctes agamemnon (Coleoptera: Scarabaeidae). BMC Microbiol 15(1):-10

Hasan S, Ahmad A, Purwar A, Khan N, Kundan R, Gupta G (2013) Production of extracellular enzymes in the entomopathogenic fungus Verticillium lecanii. Bioinformation 9(5):238-242

Humber RA (1997) Fungi: Identification. USDA-ARS Plant Protection Research Unit, US Plant, Soil \& Nutrition Laboratory, Tower Road, Ithaca, New York, USA. pp153-185

Ibrahim RA (2017) Laboratory evaluation of entomopathogenic fungi, commercial formulations, against the rhinoceros beetle, Oryctes agamemnon arabicus (Coleoptera: Scarabaeidae). Egypt J Biol Pest Cont 27(1):49-55

Ibrahim RA, Alahmadi S (2015) Effect of Syzygium aromaticum cloves on larvae of the rhinoceros beetle, Oryctes agamemnon (Coleoptera: Scarabaeidae). Afr Entomol 23(2):458-466

Khalaf M, Al Rubeae H, Al-Taweel A, Naher F (2013) First record of Arabian rhinoceros beetle, Oryctes Agamemnon aerobics Fairmaire on date palm trees in Iraq. Agric Biol J N Am 4(3):349-351

Khan S, Guo L, Shi H, Mijit M, Qiu D (2012) Bioassay and enzymatic comparison of six entomopathogenic fungal isolates for virulence or toxicity against green peach aphids Myzus persicae. Afr. J. Biotechnol. 11(77):14193-14203

Khudhair M, Khalaf M, Alrubeai H, Shbar A, Hamad B, Khalaf H (2015) Evaluating the virulence of Metarhizium anisopliae (Deuteromycotina: Hyphomycetes) and Beauveria bassiana (Ascomycota: Hypocreales) isolates to Arabian rhinoceros beetle, Oryctes agamemnon arabicus. J Entomol Acarol Res 47: $117-122$

Latifian M, Rad B (2012) Pathogenicity of the entomopathogenic fungi Beauveria bassiana (Balsamo) Vuillmin, Beauveria brongniartii Saccardo and Metarhizium anisopliae Metsch to adult Oryctes elegans Prell and effects on feeding and fecundity. Inter J Agri Crop Sci 4(14):1026-1032

Liu L, Zhan R, Yang L, Liang C, Zeng D, Huang J (2015) Isolation and identification of Metarhizium anisopliae from Chilo venosatus (Lepidoptera: Pyralidae) cadaver. Afr J Biotechnol 11:7609-7617

Mishra S, Kumar P, Malik A (2013) Effect of process parameters on the enzyme activity of a novel Beauveria bassiana isolate. Inter J Cur Microbiol Appl Sci 2(9):49-56 
Mondal S, Baksi S, Koris A, Vataig G (2016) Journey of enzymes in entomopathogenic fungi. Pacific Science Review A: Natural Science and Engineering 18:85-99

Nong X, Liu C, Lu X, Wang Q, Wang G, Zhang Z (2011) Laboratory evaluation of entomopathogenic fungi against the white grubs, Holotrichia oblita and Anomala corpulenta (Coleoptera: Scarabaeidae) from the field of peanut, Arachis hypogaea. Biocontrol Sci Tech 21(5):593-603

Pedrini N, Zhang S, Juárez MP, Keyhani NO (2010) Molecular characterization and expression analysis of a suite of cytochrome P450 enzymes implicated in insect hydrocarbon degradation in the entomopathogenic fungus Beauveria bassiana. Microbiology 156:2549-2557

Pernfuss B, Zelger R, Kron-Morelli R, Strasser H (2005) Control of the garden chafer Phyllopertha horticola with GranMet-P, a new product made of Metarhizium anisopliae. Insect pathogens and insect parasitic nematodes: Melolontha. IOBCNPRS Bull 28(2):47-50

Petlamul W, Prasertsa P (2012) Evaluation of strains of Metarhizium anisopliae and Beauveria bassiana against Spodoptera litura on the basis of their virulence, germination rate, conidia production, radial growth and enzyme activity. Mycobiology 40(2):111-116

Petrisor C, Stoian G (2017) The role of hydrolytic enzymes produced by entomopathogenic fungi in pathogenesis of insects. Rom J Plant Prot X:66-72

Sumantha A, Larrochhe C, Pandey A (2006) Microbiology and industrial biotechnology of food-grade proteases: a perspective. Food Technol Biotechnol 44:211-220

Zare M, Talaei-Hassanloui R, Fotouhifar K (2014) Relatedness of proteolytic potency and virulence in entomopathogenic fungus Beauveria bassiana isolates. J Crop Prot 3(4):425-434

Zelazny B, Lolong A, Pattang B (1992) Oryctes rhinoceros (Coleoptera: Scarabaeidae) populations suppressed by a baculovirus. J Invertebr Patho 59(1):61-68

Zhang S, Widemann E, Bernard G, Lesot A, Pinot F, Pedrini N, Keyhani NO (2012) CYP52X1, representing new cytochrome P450 subfamily, displays fatty acid hydroxylase activity and contributes to virulence and growth on insect cuticular substrates in entomopathogenic fungus Beauveria bassiana. J Biol Chem 287(16):13477-13486

Zhang S, Xia Y, Keyhani NO (2011) Contribution of the gas1 gene of the entomopathogenic fungus Beauveria bassiana, encoding a putative glycosylphosphatidylinositol-anchored beta-1,3-glucanosyltransferase, to conidial thermotolerance and virulence. Appl Environ Microbiol 77:2676-2684

\section{Submit your manuscript to a SpringerOpen ${ }^{\circ}$ journal and benefit from:}

- Convenient online submission

- Rigorous peer review

- Open access: articles freely available online

- High visibility within the field

- Retaining the copyright to your article

Submit your next manuscript at $\boldsymbol{\nabla}$ springeropen.com 